\title{
Nanomembrane-based Apheresis as Safe and Effective Therapy for Cytomegalovirus and Epstein-Barr Virus Reactivation
}

\author{
Vjeroslava Slavic $^{1,2 *} \mathbb{D}$, Beti Djurdjic ${ }^{2}$ D, Danijela Randjelovic ${ }^{1,2}$ (D) Gordana Rajovic ${ }^{2}$, Marina Delic ${ }^{1,2}$ (D) \\ ${ }^{1}$ Cabinet for Apheresis, Institute for Physical medicine, Rehabilitation and Rheumatology, "Dr Simo Milosevic", Igalo, Montenegro; \\ ${ }^{2}$ Centre of Excellence for Biomedical Researches, Institute for Physical medicine, Rehabilitation and Rheumatology, "Dr Simo \\ Milosevic", Igalo, Montenegro
}

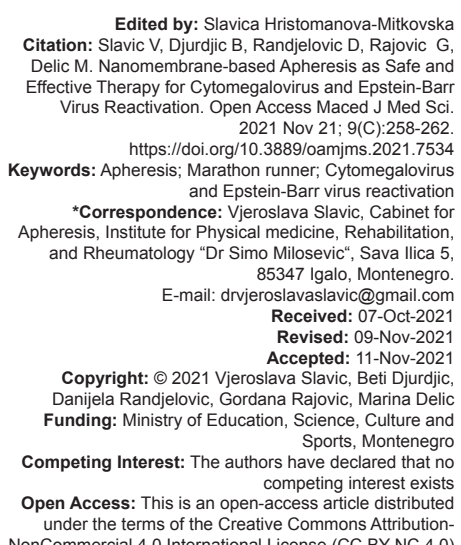

\section{Abstract}

BACKGROUND: Heavy training schedules or endurance competitions in marathon are forms of extreme physical stress and lead to immunodepression in runners which could be associated with increased susceptibility to vira reactivation by ubiquitous viral infection such as cytomegalovirus (CMV) and Epstein-Barr virus (EBV). Lately, it was confirmed presence of elevated CMV and EBV loads and the lower antibody titers in competitive athletes. The most common clinical features are fatigue and adynamia accompanied with liver damage, varying from mild and transient elevation of aminotransferases to serious acute hepatitis and liver failure.

CASE REPORT: Bearing in mind that a professional practice of marathon running is hazardous for the liver, therapeutic action is necessary as soon as possible to avoid serious complications and even cessation of professional competition. In our case report of professional female marathon runner, we need to treat CMV and EBV reactivation which caused liver damage, prevented regular trainings, and upcoming competitions. We opted for four sessions of nanomembrane based apheresis performed every other day for removal pathological products resulting from virus reactivation to break through the course of the disease and to prevent complications. After completing the whole procedure control laboratory tests and abdominal ultrasound were in physiological ranges.

CONCLUSION: Hence, nanomembrane based apheresis can be effective and safe treatment of liver damages for elite marathon runners as well as for athletes.

\section{Introduction}

The human herpesviridae family shows a high percentage of seroprevalence the population worldwide. It is estimated that 50 to as many as $100 \%$ of healthy people have positive rates of antibodies to cytomegalovirus (CMV) and up to $90 \%$ for EpsteinBarr virus (EBV) [1], [2]. After primary infection by CMV and/or EBV, a lifelong latency develops and under certain conditions they may be reactivated. However, latent viruses can often reactivate without conspicuous symptoms of infection, particularly during or shortly after periods of the high physical and/or psychological stress as a consequence of immune depression in athletes [3], [4]. Indeed, viral reactivation has been linked with acute and chronic stress [5], [6] and these may be exacerbated by frequent training and competition [7]. Their reactivation can lead to varying liver damage from a mild and transient elevation of aminotransferases to acute hepatitis and liver failure [8]. According to the literature, fatigue and adynamia were the most common clinical features [9].
Marathon running has been intensively studied to better understand the impact on elite athlete's health and well-being. However, it was pointed out that heavy training schedules or endurance competitions, such as marathons, are forms of extreme physical stress and lead to immunodepression in athletes, which is associated with increased susceptibility to infection [10]. The trend of recent years shows an increased duration, intensity, and difficulty of training, a high-frequency participation in sports event which negatively affects the risk of infections including viral reactivations [11]. Recurrent infections, mild or severe, can cause frequent interruptions, lack or stagnation of performance, retirement from competitive sports, furthermore, and influencing long-term everyday life [12].

In this regard, the problem of finding additional therapeutic measures for faster recovery of liver damage caused by reactivation of CMV and EBV viruses in professional marathon runners remains a challenge. More recently, special attention has been drawn to therapeutic apheresis which is used for the treatment more than 75 different diseases including viral infections [13]. It is considered as a pathogenetically 
justified method for treating and preventing the progression of liver damage [14]. Apheresis is a method of efferent therapy in which patients' blood is passed through a medical device that separates the plasma from other component of the blood. Plasma is removed and replaced by a plasma replacement solution (for example: Albumin, $\mathrm{NaCl} 0.9 \%$, and donor plasma) [15].

Here, we wanted to show the effects of the apheresis of a professional marathon runner who felt tired and exhausted due to the reactivation of the CMV and EBV viruses, which are why she had to stop regular preparatory training for the season.

\section{Case Report}

A 37-year-old female, a professional marathon runner, applied for an immunological examination due to faster fatigue during the usual training, which she noticed a month ago without any other accompanying symptoms. During that period, she did not have febrility or sore throat. Regularly, she takes following supplements oligominerals calcium $(\mathrm{Ca})$, magnesium $(\mathrm{Mg})$ and zinc $(\mathrm{Zn})$, Vitamins B complex and D, Aspirin, $\beta$ alanine, and inosine. Possible severe acute respiratory syndrome coronavirus 2 infection is excluded - Immunoglobulins G (IgG) 0.02 (17 May 2021). Laboratory parameters (May 18, 2021) pointed on liver damage (Aspartate and Alanine Transaminase: AST 66.6, ALT 127.3) without increase acute phase reactants (C-reactive protein: 1.19), leukocytes 6.64 (Granulocyte 54.6, Lymphocyte 34.4 , and Monocyte $7.53 \%$ ), erythrocytes 4.93 , hemoglobin 136, hematocrit 0.436 , and platelets 386 . Serological tests (May 29, 2021) showed elevated IgG concentrations for EBV $(39.9 \mathrm{U} / \mathrm{ml})$ and $\mathrm{CMV}(39.4 \mathrm{U} / \mathrm{ml})$, while their concentrations in the IgM fraction were negative/non-reactive. Abdominal ultrasound (April 01,2021 .) showed a slight enlargement of the liver, a homogeneous somewhat coarser structure without focal lesions; spleen of marginal size, homogeneous structure of parenchyma with accessory structure in hilus.

According to perform diagnostic procedures, it was indicated treatment with membranous apheresis at the institute "Dr Simo Milosevic" Igalo. After the patient was acquainted with the technique of performing the procedure, the expected results, and possible risks, she signed the consent and the treatment began on April 14, 2021. The procedure consisted of four cycles of membranous apheresis on a Hemofenix device (Trackpore Technology, Russia) (Figure 1a-1) with PFM 500 filters (Plasmofilter, Russia) (Figure 1a-3) performed every other day in the period from April 14, 2021 to April 20, 2021. Before each cycle, the patient had premedication which consisted of 5000 IU Heparin in a bolus with $5000 \mathrm{IU}$ Heparin in $500 \mathrm{ml}$ saline. In

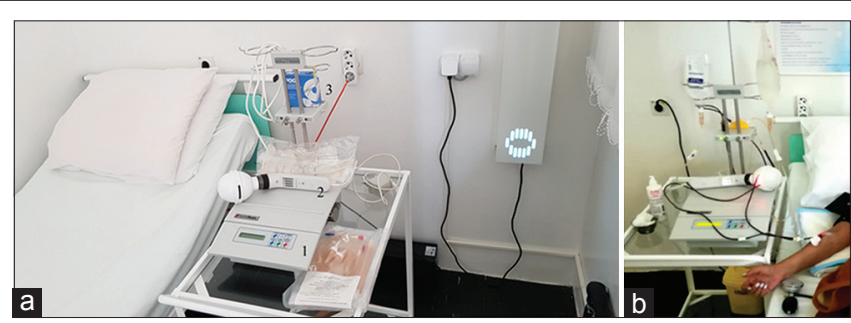

Figure 1: (a) 1 - Hemofenix device, 2 - Rubin Laser, and 3 - PFM 500 filters; (b) Presentation of apheresis procedure

addition, extracorporeal photomodification of blood was performed during each cycle using laser, red, and infrared beams (Rubin Laser, Russia) (Figure 1a-2). Apheresis procedure is shown in Figure $1 \mathrm{~b}$.

Before the procedure, it was measured: Body weight $56,200 \mathrm{~kg}$, body height $168 \mathrm{~cm}$, body mass index 19.84, blood pressure 120/75, and pulse rate $77 / \mathrm{min}$. Further, it was calculated volume of circulated blood $(3934 \mathrm{ml})$ as well as plasma volume $(2333 \mathrm{ml})$. During individual cycles, a volume of $2900-3700 \mathrm{ml}$ (average $3250 \mathrm{ml}$ ) of circulating blood was processed, and $600-700 \mathrm{ml}$ of plasma (average $625 \mathrm{ml}$ ) or $26-30 \%$ of the plasma volume was removed. There were no complications and side effects during procedures.

The protocol data of each individual procedure cycle are shown in Table 1.

Table 1: Protocol of membranous apheresis procedure - extracorporeal chemo correction

\begin{tabular}{lllll}
\hline Measured values & I cycle & II cycle & III cycle & IV cycle \\
\hline Blood stabilization-ACD-A (ml) & 290 & 230 & 150 & 200 \\
Processed blood volume $(\mathrm{ml})$ & 2900 & 3100 & 3300 & 3700 \\
Removed plasma volume $(\mathrm{ml})$ & 600 & 600 & 700 & 600 \\
Replaced volume of 0.9\% NaCl $(\mathrm{ml})$ & 500 & 900 & 700 & 500 \\
\hline ACD-A: Anticoagulant Citrate Dextrose Solution. & & & &
\end{tabular}

The achieved effect of individual cycles is seen through the appearance of the removed plasma (Figure 2).

Complete blood count immediately before the first cycle and immediately after the fourth cycle of the procedure is shown in Table 2.

Table 2: Complete blood count immediately before the first and immediately after the fourth cycle of apheresis

\begin{tabular}{lll}
\hline $\begin{array}{l}\text { Measured } \\
\text { values }\end{array}$ & Before the first cycle & Immediately after the fourth cycle \\
\hline Erythrocytes & 4.98 & 5.36 \\
Hemoglobin & 137 & 143 \\
Hematocrit & 40.7 & 43.9 \\
MCV & 81.7 & 81.9 \\
MCH & 27.5 & 26.7 \\
MCHC & 337 & 326 \\
Leukocytes & 6.7 & 7.4 \\
Lymphocytes & 26.2 & 34.1 \\
Monocytes & 3.2 & 2.4 \\
Granulocytes & 70.6 & 63.5 \\
Platelets & 346 & 322 \\
\hline MCV: Mean corpuscular volume, MCH: Mean corpuscular hemoglobin, MCHC: Mean corpuscular
\end{tabular}

Hepatogram before the first cycle, after the fourth cycle and 7 days after apheresis are shown in Table 3.

Control ultrasound of the abdomen (April 26,2021 ) - liver of appropriate size, homogeneous structure without signs of focal changes. Spleen of appropriate size and neat echo structure. 
Table 3: Hepatogram before the first cycle, after the fourth cycle and 7 days after apheresis

\begin{tabular}{llll}
\hline Measured parameters & Before the first cycle (April 14, 2021) & After the fourth cycle (April 20, 2021) & Seven days after Apheresis (April 27, 2021) \\
\hline AST (U/L) & 46 & 32 & 31 \\
ALT (U/L) & 115 & 68 & 46 \\
LDH (U/L) & 274 & 238 & 222 \\
GGT (U/L) & 55 & 22 & 21 \\
CRP (mg/dL) & 7.6 & 6.5 & 1.6 \\
\hline AST
\end{tabular}

$\mathrm{CRP}(\mathrm{mg} / \mathrm{dL})$ 6.5

After completing the apheresis procedure, the patient stated that the feeling of fatigue was significantly reduced, physical abilities and quality of sleep were improved, while the subjective feeling of energy was increased.

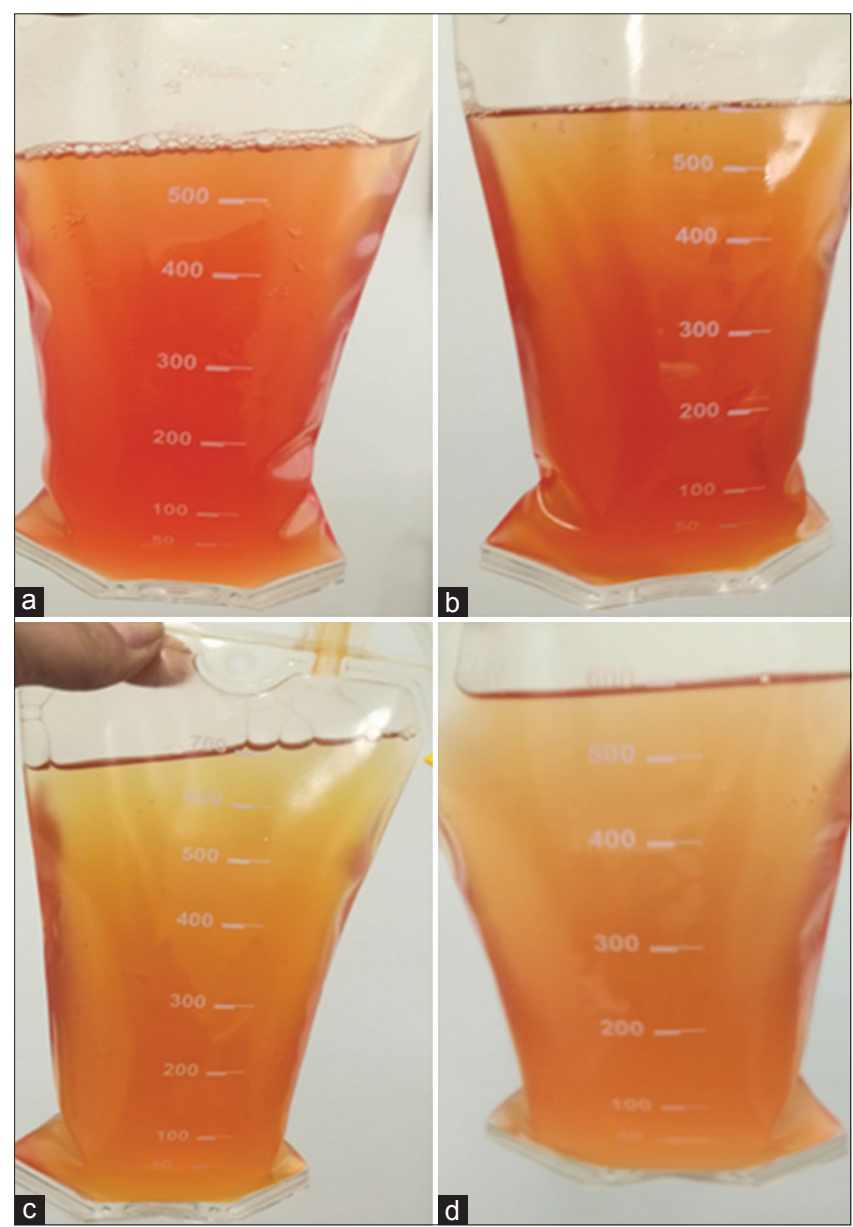

Figure 2: Appearance of removed blood plasma after the first (a), second (b), third (c), and fourth (d) cycles of the apheresis procedure

\section{Discussion}

In recent years, the practice of marathons has become extremely popular to prevent diseases associated with progress of civilization. However, professional marathon runners are exposed to prolonged physical stress accompanied with liver and skeletal muscles damages, metabolic depletions as well as dysregulation of immune system. Moreover, high-intensity or extensive training loads transiently diminish the immune competence [16]. Hence, it was suggested a weaker immune function in competitive athletes [17].

Diminish performance and fatigue are often associated with EBV and CMV infections in elite athletes [18]. The viruses persist lifelong in the organism, and they controlled by the adaptive immune system, which is measured by detection of specific antibodies in the sera [19].

If the viruses are reactivated, the adaptive immune system responds by both cellular and humoral components with the consequent formation of circulating immune complexes and production of inflammatory mediators. It is necessary to detoxicate organism with removal pathological products resulting from virus reactivation to break through the course of the disease and to prevent complications. For this purpose, apheresis is the most effective therapy in removal pathological products and all components incompetent humoral immunity [20].

The reasons that make nanomembrane based Apheresis the most effective approach for viral infections are (1) rapid control of quantitative and qualitative abnormalities of plasma and/or blood components, (2) semi-permeable nanomembrane can localized immunologically active compounds (pathological antigens or antigen-antibody complexes) on its surfaces, (3) addition of extracorporeal laser blood irradiation reactivate antioxidant protection as well as increase immunomodulatory and anti-inflammatory effects by lymphocytes and macrophages activation [13],[21]. Comparing to standard protocols in treatment of viral infections advantages are decrease treatment period through faster elimination viral antigens, prevent further liver cells damages and restoration of immune system, adaptive and innate. However, disadvantage of nanomembrane based Apheresis is expensiveness compared to the usual treatment.

Even more, American Society for Apheresis in 2013 approved this kind of procedure as minimally invasive and safe because it is performed on a single needle and removed plasma is replaced by saline solution [22]. According to the literature, apheresis procedure in combination with extracorporeal laser blood irradiation could be a highly effective therapeutic tool in the prevention of brain damage caused by HSV1 encephalitis [23].

Liver damage in professional marathon runners caused by reactivation of hepatotropic CMV and EBV includes combination of more pathogenetic mechanisms with the consequent accumulation 
toxic products and increased levels of AST and ALT as parameters of hepatocyte cell damage. Basic physiological mechanisms imply that pathogenetic agents and produced toxic mediators are first present intravascular. Later, as the process progresses, they can leaky into the interstitial and intracellular department. Since the apheresis procedure removes pathological substrates from the blood or intravascularly, their effective removal from the body requires repeating the procedure at defined time intervals.

Hence, we apply procedure consisted of four sessions of nanomembrane based apheresis with additional extracorporeal laser beam irradiation of blood for the detoxication body of the pathological substrates create by CMV and EBV reactivation. The sessions held every other day and in each of them safely removed approximately $600 \mathrm{ml}$ of plasma or $25 \%$. Immediately, after finished the whole procedure, concentration of AST and ALT significantly decreased. According to the performed control abdominal ultrasound and laboratory tests 1 week later, the progression of liver damages was effectively interrupt. Our professional female marathon runner started with regular training process 1 week after finishing apheresis treatment, and 2 months later takes part on European league competition.

\section{Conclusion}

Professional marathon runners are exposed to ubiquitous viral infection such as CMV and EBV bearing in mind their prevalence in the general population. Adding to that the fact that a marathon in elite running is a hazardous for the liver, the principle of treatment must be adapted to the need to preserve liver tissue and function. Four sessions of nanomembrane based apheresis, every other day, can be effective and safe treatment of liver damages in elite marathon runners.

\section{Acknowledgments}

The authors want to express a special thanks to late Prof Voinov (1938-2021) as the creator of this innovative procedure. Prof Voinov was our great support for education and implementation of this procedure at the Institute for Physical medicine, Rehabilitation, and Rheumatology, Dr Simo Milosevic Igalo, Montenegro.

The authors declare no conflict of interest. The present study complies with the present laws of the country in which the study was performed.

\section{References}

1. Gandhi MK, Khanna R. Human cytomegalovirus: Clinical aspects, immune regulation, and emerging treatments. Lancet Infect Dis. 2004;4(12):725-38. https://doi.org/10.1016/ S1473-3099(04)01202-2

PMid:15567122

2. Maeda A, Sato T, Wakiguchi H. Epidemiology of Epstein-Barr virus (EBV) infection and EBV-associated diseases. Nihon Rinsho. 2006;64(3):609-12.

PMid: 16615544

3. Crucian B, Simpson RJ, Mehta S, Stowe R, Chouker A, Hwang SA, et al. Terrestrial stress analogs for spaceflight associated immune system dysregulation. Brain Behav Immun. 2014;39:23-32. https://doi.org/10.1016/j.bbi.2014.01.011 PMid:24462949

4. Mehta SK, Crucian BE, Stowe RP, Simpson RJ, Ott CM, Sams CF, et al. Reactivation of latent viruses is associated with increased plasma cytokines in astronauts. Cytokine. 2013;61(1):205-9. https://doi.org/10.1016/j.cyto.2012.09.019 PMid:23107825

5. Glaser R, Friedman SB, Smyth J, Ander R, Bijur P, Brunell $P$ et al. The differential impact of training stress and final examination stress on herpesvirus latency at the United States military academy at west point. Brain Behav Immun. 1999;13(3):240-51. https://doi.org/10.1006/brbi.1999.0566 PMid: 10469525

6. Sarid O, Anson O, Yaari A, Margalith M. Human cytomegalovirus salivary antibodies as related to stress. Clin Lab. 2002;48(5-6):297-305.

PMid: 12071580

7. Walsh NP, Gleeson M, Pyne DB, Nieman DC, Dhabhar FS, Shepard RJ, et al. Position statement. Part two: Maintaining immune health. Exerc Immunol Rev. 2011;17:64-103.

PMid:21446353

8. Gallegos-Orozco JF, Rakela-Brodner J. Hepatitis viruses: Not always what it seems to be. Rev Med Chil. 2010;138(10):1302-11. PMid:21279280

9. Mendez-Sanchez N, Aguilar-Dominguez C, Chavez-Tapia NC, Urube M. Hepatic manifestations of Epstein-Barr viral infection. Ann Hepatol. 2005;4(3):205-9.

PMid:16177662

10. Gleeson M, Nieman DC, Pedersen BK. Exercise, nutrition and immune function. J Sports Sci. 2004;22(1):115-25. https://doi. org/10.1080/0264041031000140590

PMid: 14971437

11. Armstrong N, Mc Manus AM. The elite young athlete. Med Sport Sci. 2011;56:1-3. https://doi.org/10.1159/ isbn.978-3-8055-9551-3

12. Whittaker JL, Woodhouse LJ, Nettel-Aguirre A, Emery CA. Outcomes associated with early post-traumatic osteoarthritis and other negative health consequences 3-10 years following knee joint injury in young sport. Osteoarthritis Cartilage. 2015;23(7):1122-9. https://doi.org/10.1016/j.joca.2015.02.021 PMid:25725392

13. Alexandrov AS, Vassileva $P$, Momchilova A,Tsoncev Z, Kirilova $\mathrm{Y}$, Ivanova $\mathrm{R}$, et al. A new approach using nanomembrane-based therapeutic plasmapheresis for treatment of patients with multiple sclerosis and neuromyelitis optica. Bulgarian Academy of Sci. 2016;69(3):373-84. Available from: https://www.researchgate.net/publication/301753035_A_ new_approach_using_nanomembrane-based_therapeutic plasmapheresis_for_treatment_of_patients_with_multiple_ 
sclerosis_and_neuromyelitis_optica

14. Voinov VA, Karchevskz KS, Isauliv OV. Plasmapheresis in the treatment of chronic liver diseases. Acta Sci Gastrointest Disord. 2019;2(4):28-38.

15. Schwartz J, Padmanabhan A, Aqui N, Balogun RA, ConnellySmith L, Delaney M, et al. Recommendation on the application of therapeutic apheresis in clinical practice-based editorial committee for apheresis: Seventh special edition. Part 1. American society for apheresis (ASFA). J Clin Apher. 2016;31:149-338.

16. Spence L, Brown WJ, Pyne DB, Nissen MD, Sloots TP, McCormack JG, et al. Incidence, etiology, and symptomatology for upper respiratory illness in elite athletes. Med Sci Sports Exerc. 2007;39(4):577-86. https://doi.org/10.1249/ mss.0b013e31802e851a

PMid: 17414793

17. Hoffmann D, Wolfarth B, Horterer HG, Halle M, Reichhuber C, Nadas $\mathrm{K}$, et al. Elevated Epstein-Barr virus loads and lower antibody titers in competitive athletes. J Med Virol. 2010;82(3):446-51. https://doi.org/10.1002/jmv.21704 PMid:20087932

18. Balfour HH, Dunmire SK, Hogquist KA. Infectious mononucleosis. Clin Transl Immunology. 2015;4(2):e33. https://doi.org/10.1038/ cti.2015.1

PMid:25774295

19. de Paschale M, Clerici P. Serological diagnosis of Epstein-Barr virus infection: Problem and solution. World J Virol. 2012;1(1):3143. https://doi.org/10.5501/wjv.v1.i1.31

PMid:24175209

20. Voinov VA. Therapeutic apheresis in metabolic syndrome Immunol Endocr Metab Agents Med Chem. 2018;18(1):38-54. https://doi.org/10.2174/1871522218666180608114536

PMid:30369968

21. Voinov VA. Plasmapheresis for Critically III Patients. SaintPetersburg:Novosti;2014. p. 13.

22. Schwartz J, Winters JL, Aqui N, Balogun RA, Connelly-Smith L, et al. Guidelines on the use of therapeutic apheresis in clinical practice-evidence-based approach from the writing committee of the American society for apheresis: The sixth special issue. J Clin Apher. 2013;28(3):145-284. https://doi.org/10.1002/ jca. 21276

PMid:23868759

23. Slavic V. Apheresis procedure could prevent sequele of HSV1 encephalitis-case report. Ann Antivir Antiretrovir. 2020;4(1):10-3. https://doi.org/10.17352/aaa.000009 